\title{
Treatment of Cervicogenic Headache: New Insights on the Treatment of Pain in the Neck
}

This manuscript served as a companion piece for the original article "Pregabalin for the Management of Cervicogenic Headache; A Double Blind Study" by Guy P. Boudreau and Luc Marchand, which was published in the September 2014 issue of The Canadian Journal of Neurological Sciences. ${ }^{1}$

doi:10.1017/cjn.2015.274

Can J Neurol Sci. 2015; 42: 357-359

Diagnosis and treatment of cervicogenic headache are both clinically challenging; as a result, this disorder remains one of the most controversial in headache medicine. ${ }^{2}$ Between $50 \%$ and $75 \%$ of patients with whiplash injury may have headache related to a disorder of the neck, ${ }^{3}$ whereas in the general population, the prevalence of cervicogenic headache has been estimated to be $4.1 \%{ }^{4}$ Given that the pathology in cervicogenic headache is thought to lie in the cervical spine area, the mechanism of the actual head pain, which often involves the frontal and temporal areas, likely relates to convergence between cervical nociceptive and trigeminal afferents in the trigeminocervical complex at in the upper cervical spine. ${ }^{5}$

Diagnostic criteria for cervicogenic headache were published by Sjaastad et al in $1998,{ }^{6}$ and these were the diagnostic criteria used by Boudreau et $\mathrm{al}^{1}$ when selecting patients for their study, which is published in the Canadian Journal of Neurological Sciences. Boudreau et $\mathrm{al}^{1}$ required that all patients have strictly unilateral headache without side shift. Their patients also had to be severely affected in that at least 4 hours of continuous pain of moderate to severe intensity per day were required, and patients had to have headache on at least 15 days per month. Finally, patients had to have an abnormal neck examination with what they termed signs of neuropathic involvement in the territory of the upper cervical nerve roots. The presence of allodynia - in other words, some degree of central sensitization-appears to have been sufficient to meet this criterion.

The Third Edition of the International Classification of Headache Disorders (ICHD-3 beta) divides chronic daily headache related to the neck into two disorders. ${ }^{7}$ The first is persistent headache attributed to whiplash. It is defined as a new headache of any phenotype that begins within 7 days of a whiplash injury, lasts at least 3 months, and is not better accounted for by another diagnosis. The second headache type related to the neck is cervicogenic headache. This is defined as a headache that occurs in a patient with clinical, laboratory, or imaging evidence of a neck disorder known to cause headache. Several criteria are given that are considered to provide evidence of causation, and the headache should not be better accounted for by another diagnosis. Of note, in the study by Boudreau et al, at least $85 \%$ of patients were reported to have neck trauma as a triggering factor; therefore, the majority of their patients may have fallen into the category of persistent headache attributed to whiplash headache as defined by the ICHD-3. Both the Sjaastad criteria and the ICHD-3 criteria for cervicogenic headache stress the importance of pain abolition by anesthetic blockade of cervical structures, although in the ICHD-3 criteria such blockade is no longer mandatory for the diagnosis. Diagnostic nerve blocks were not used by Boudreau et al in this study, and in fact patients booked for somatic nerve blocks were excluded. Patients appear to have been diagnosed purely on clinical features.

The neck has many potential pain generators. Clinical studies have indicated that the $\mathrm{C} 2-3$ zygapophysial joints are one of the most common sources of pain in cervicogenic headache, particularly in those with whiplash injury or motor vehicle accidents, accounting for $50 \%$ of cases. ${ }^{8,9}$ Unfortunately, manual examination is not reliably accurate in detecting zygapophysial joint pain, nor is medical imaging beneficial in localizing the pain generator. ${ }^{2,5}$ Studies with magnetic resonance imaging in patients with cervicogenic headache reported no demonstrable differences in the appearance of cervical spine structures on magnetic resonance imaging scans in comparison with control subjects and subjects with other headache disorders. ${ }^{10,11}$ Imaging, therefore, plays a role primarily to assess other causes of headache that may require surgical treatment. To achieve pain control of cervicogenic headache, it would appear best to employ a multimodal approach with pharmacological, manipulative, ${ }^{12-15}$ anesthetic, ${ }^{16-22}$ and invasive interventions. ${ }^{23,24}$

Medications alone are often ineffective or provide only modest benefit for cervicogenic headache. ${ }^{25}$ Medications commonly used include antidepressants, antiepileptic drugs, analgesics, and muscle relaxants, ${ }^{25}$ but none of these medications has been studied in controlled clinical trials. Medical management of cervicogenic headache therefore relies on the anecdotal experience of clinicians and/or is based on treatment of other headache disorders. A patient with headache following whiplash injury who demonstrated a substantial response to treatment with botulinum toxin $^{26}$ has been reported, but a randomized controlled trial of botulinum toxin in cervicogenic headache was negative. ${ }^{27}$ It may be, however, that optimal injection protocols for cervicogenic headache have not yet been developed.

Boudreau et al report a single center, double-blind, randomized controlled study on the use of pregabalin in patients with cervicogenic headache in a relatively severely affected patient cohort. To be included, patients had to have proven refractory to commonly used medications including neuromodulators, muscle relaxants, tricyclics, and nonsteroidal anti-inflammatory drugs. Patients were excluded if they used rescue medications 
(presumably analgesics) on more than 15 days a month. After a 1-month baseline period, patients received pregabalin or placebo for 12 weeks. The patient cohort was quite severely affected, in that patients in the study had headache during baseline on a mean of 26 days per month.

Given the many exclusion criteria, including previous use of pregabalin, recruitment for the study was obviously difficult. Retention was also difficult. Forty-one patients were randomized, but only 28 completed the study. Thirty-four patients (18 pregabalin, 16 placebo) could be included in a modified intent-to-treat analysis. Pregabalin was uptitrated to a maximal dose of $450 \mathrm{mg}$ per day, although half of the patients in the pregabalin group remained at lower doses.

Despite the small size of this study, it was able to show a significant benefit of pregabalin compared with placebo in the primary endpoint — number of headache days per month-during the last month of the study. Days with headache in the pregabalin group decreased from 26 to 16 days per month (a 10-day-per-month reduction) compared with a reduction of just over 2 days per month in the placebo group $(p=0.013)$. Many of the secondary endpoints including reduction in headache intensity also showed a trend for greater improvement in the pregabalin group compared with placebo, although these were not statistically significant. The reduction in headache intensity, although not significant in this small patient sample, appeared clinically potentially very relevant. Interestingly, the pregabalin group also showed a trend for improvement in anxiety and depression compared with the placebo group.

Boudreau et al are to be congratulated for completing a meaningful clinical trial in this difficult patient population. Their study is small, but it provides randomized controlled trial support for the use pregabalin in cervicogenic headache, including cases related to previous trauma. It should be noted, however, that all patients in this trial were required to have evidence on examination of neuropathic involvement in the $\mathrm{C} 2$ or $\mathrm{C} 3$ distribution with hyperesthesia, hypoesthesia, dysesthesia, allodynia, or hyperalgesia. The generalizability of their findings to all patients with cervicogenic headache therefore cannot be assumed. Pregabalin has been widely used in patients with neuropathic pain and has US Food and Drug Administration approval for use in neuropathic pain syndromes including diabetic neuropathy, postherpetic neuralgia, and neuropathic pain in spinal injury. It is also known to have anxiolytic properties. These factors may explain the positive results of pregabalin on pain and mood in this study. It is unclear at this point whether pregabalin is beneficial in patients with cervicogenic headache without clinical neuropathic involvement. As the authors point out, further research and larger studies are needed to define the role of pregabalin in the treatment of cervicogenic headache, but the randomized controlled trial by Boudreau et al is certainly an important step in the right direction. The authors are to be congratulated on a study, which finally casts some scientific light on the medical treatment of this controversial and often refractory headache disorder.

\section{ACKNOWLEDGMENTS}

PC has nothing to disclose. WB has served as a consultant/speaker and received consulting fees from Allergan; served as a speaker and received honorarium from Tribute, Teva, and Serono; been a consultant and received consulting fees from Electrocore and St. Jude; and been a principal investigator and received grants from Amgen.

\section{Prin Chitsantikul \\ Werner J. Becker \\ University of Calgary and Alberta Health Services \\ Calgary, Alberta, Canada \\ E-mail: prin.chitsantikul@albertahealthservices.ca}

\section{REFERENCES}

1. Boudreau GP, Marchand L. Pregabalin for the management of cervicogenic headache: a double blind study. Can J Neurol Sci. 2014;41:603-10.

2. Becker WJ. Cervicogenic headache: evidence that the neck is a pain generator. Headache. 2010;50:699-705.

3. Rana MV. Managing and treating headache of cervicogenic origin. Med Clin North Am. 2013;97:267-80.

4. Sjaastad O. Cervicogenic headache: comparison with migraine without aura; Vaga study. Cephalalgia. 2008;28(Suppl 1):18-20.

5. Bogduk N, Govind J. Cervicogenic headache: an assessment of the evidence on clinical diagnosis, invasive tests, and treatment. Lancet Neurol. 2009;8:959-68.

6. Sjaastad O, Fredriksen TA, Pfaffenrath V. Cervicogenic headache: diagnostic criteria. The Cervicogenic Headache International Study Group. Headache. 1998;38:442-5.

7. The International Classification of Headache Disorders, 3rd ed. (beta version). Cephalalgia. 2013;33:629-808.

8. Lord SM, Barnsley L, Wallis BJ, Bogduk N. Third occipital nerve headache: a prevalence study. J Neurol Neurosurg Psychiatry. 1994;57:1187-90.

9. Cooper G, Bailey B, Bogduk N. Cervical zygapophysial joint pain maps. Pain Med. 2007;8:344-53.

10. Knackstedt H, Krakenes J, Bansevicius D, Russell MB. Magnetic resonance imaging of craniovertebral structures: clinical significance in cervicogenic headaches. J Headache Pain. 2012;13:39-44.

11. Coskun O, Ucler S, Karakurum B, et al. Magnetic resonance imaging of patients with cervicogenic headache. Cephalalgia. 2003;23:842-5

12. Haas M, Spegman A, Peterson D, Aickin M, Vavrek D. Dose response and efficacy of spinal manipulation for chronic cervicogenic headache: a pilot randomized controlled trial. Spine J. 2010;10:117-28.

13. Hall T, Chan HT, Christensen L, Odenthal B, Wells C, Robinson K. Efficacy of a $\mathrm{C} 1-\mathrm{C} 2$ self-sustained natural apophyseal glide (SNAG) in the management of cervicogenic headache. J Orthop Sports Phys Ther. Mar37:100-7.

14. Jull G, Trott P, Potter H, Zito G, Niere K, Shirley D, et al. A randomized controlled trial of exercise and manipulative therapy for cervicogenic headache. Spine (Phila Pa 1976). 2002;27:1835-43.

15. Nilsson N, Christensen HW, Hartvigsen J. The effect of spinal manipulation in the treatment of cervicogenic headache. J Manipulative Physiol Ther. 1997;20:326-30.

16. Naja ZM, El-Rajab M, Al-Tannir MA, Ziade FM, Tawfik OM. Occipital nerve blockade for cervicogenic headache: a double-blind randomized controlled clinical trial. Pain Pract. 2006;6:89-95.

17. Naja ZM, El-Rajab M, Al-Tannir MA, Ziade FM, Tawfik OM. Repetitive occipital nerve blockade for cervicogenic headache: expanded case report of 47 adults. Pain Pract. 2006;6:278-84.

18. Inan N, Ceyhan A, Inan L, Kavaklioglu O, Alptekin A, Unal N. C2/ C3 nerve blocks and greater occipital nerve block in cervicogenic headache treatment. Funct Neurol. 2001;16:239-43.

19. Vincent M. Greater occipital nerve blockades in cervicogenic headache. Funct Neurol. 1998;13:78-9.

20. Bovim G, Sand T. Cervicogenic headache, migraine without aura and tension-type headache. Diagnostic blockade of greater occipital and supra-orbital nerves. Pain. 1992;51:43-8.

21. Anthony M. Cervicogenic headache: prevalence and response to local steroid therapy. Clin Exp Rheumatol. 2000;18(2 Suppl 19): S59-64. 
22. Bovim G, Fredriksen TA, Stolt-Nielsen A, Sjaastad O. Neurolysis of the greater occipital nerve in cervicogenic headache. A follow up study. Headache. 1992;32:175-9.

23. Lord SM, Barnsley L, Wallis BJ, McDonald GJ, Bogduk N. Percutaneous radio-frequency neurotomy for chronic cervical zygapophyseal-joint pain. N Engl J Med. 1996;335:1721-6.

24. Barnsley L. Percutaneous radiofrequency neurotomy for chronic neck pain: outcomes in a series of consecutive patients. Pain Med. 2005;6:282-6.
25. Biondi DM. Cervicogenic headache: a review of diagnostic and treatment strategies. J Am Osteopath Assoc. 2005; 105(4 Suppl 2):16S-22S.

26. Hobson DE, Gladish DF. Botulinum toxin injection for cervicogenic headache. Headache. 1997;37:253-5.

27. Linde M, Hagen K, Salvesen O, Gravdahl GB, Helde G, Stovner LJ. Onabotulinum toxin A treatment of cervicogenic headache: a randomised, double-blind, placebo-controlled crossover study. Cephalalgia. 2011;31:797-807. 